\title{
CAPOEIRA NAS AULAS DE EDUCAÇÃO FÍSICA: ALGUNS APONTAMENTOS SOBRE PROCESSOS DE ENSINO-APRENDIZADO DE PROFESSORES
}

\author{
Dra. PAULA CRISTINA DA COSTA SILVA \\ Professora Adjunta do Centro de Educação Física e Desporto da \\ Universidade Federal do Espírito Santo (CEFD/NFES) \\ Pesquisadora do PRÁXIS (CEFD/UFES) e LABORARTE (Faculdade de Educação/UNICAMP) \\ (Vitória - Espírito Santo - Brasil) \\ E-mail: letpau@yahoo.com.br
}

\begin{abstract}
RESUMO
Este artigo trata da capoeira e de seus processos de ensino-aprendizado a partir de uma investigação qualitativa que incluiu em sua primeira fase de pesquisa de campo um curso de formação continuada de Capoeira para professores. Nele destacamos a compreensão que temos sobre a Capoeira e a importância de sua inserção nas aulas de educação física escolar. Detalhamos como ocorreu o curso para os professores, no qual nos inserimos como participante observadora, e discutimos os processos de ensino-aprendizado nele desenvolvidos. Por fim, apontamos alguns indícios com relação às dificuldades apresentadas pelos participantes, as experiências positivas decorridas e a possibilidade de abordagem do ensino da Capoeira baseado nas interações gestuais.
\end{abstract}

PALAVRAS-CHAVE: Capoeira; educação física escolar; formação continuada de docentes; ensino-aprendizado. 
Este trabalho apresenta parte da pesquisa desenvolvida no curso de doutorado em Educação, na Faculdade de Educação, da Universidade Estadual de Campinas (UNICAMP). Trata-se de um trabalho que teve como objetivo discutir possibilidades do ensino-aprendizado da capoeira' na educação física ${ }^{2}$ escolar compreendendo-a como uma linguagem corporal na qual sua gestualidade, sua musicalidade, seus aspectos históricos e sua ritualidade compõem um acervo a ser apropriado pelos alunos.

Para atingir esse objetivo foi realizada uma pesquisa qualitativa (BOGDAN; BIKLEN, 1994) englobando um trabalho de campo dividido em duas fases, a saber: acompanhamento de um Curso de Capoeira para professores de educação física que atuam no ensino fundamental da rede pública da Região Metropolitana de Campinas $^{3}$; e o acompanhamento das aulas de capoeira desenvolvidas por duas professoras no contexto da educação física, para turmas de $1^{\mathrm{a}}$ a $4^{\mathrm{a}}$ série do antigo ensino fundamental. Em campo a pesquisadora atuou nas duas fases da investigação como participante observadora (NEGRINE, 2004) registrando os acontecimentos por meio de diário de campo, fotos e filmagens.

Neste texto nos deteremos somente ao processo de ensino-aprendizado desenvolvido no curso de formação continuada de Capoeira para professores.

\section{A CAPOEIRA NAS AULAS DE EDUCAÇÃO FÍSICA}

Considerando a educação física, a partir dos pressupostos da metodologia crítico-superadora, como uma disciplina escolar que trata pedagogicamente do que denominamos de manifestações da cultura corporal (SOARES et al., 1992) podemos pensar que o seu ensino é muito mais do que apenas executar exercícios corporais repetitivos e sem sentido. Neste caso busca-se estudar as manifestações da cultura corporal procurando compreender seus aspectos históricos, técnicos, sociológicos, antropológicos, biológicos, enfim, situando-os no contexto social no qual encontramse inseridos e instigando os alunos a realizarem uma leitura de sua realidade.

I. Neste texto a palavra Capoeira, com iniciais maiúsculas, refere-se à manifestação cultural.

2. Quando tratamos da educação física como componente curricular utilizamos suas iniciais em minúsculo, quando abordarmos a Educação Física como área do conhecimento ou campo profissional usamos suas iniciais em letras maiúsculas.

3. A Região Metropolitana de Campinas (RMC) engloba dezenove municípios paulistas: Americana, Artur Nogueira, Campinas, Cosmópolis, Engenheiro Coelho, Holambra, Hortolândia, Indaiatuba, Itatiba, Jaguariúna, Monte Mor, Nova Odessa, Paulínia, Pedreira, Santa Bárbara d'Oeste, Santo Antônio de Posse, Sumaré, Valinhos e Vinhedo. Possui uma população de 2.633 .523 habitantes desse total 39,5\% são moradores da cidade de Campinas, sede dessa região. (SÃO PAULO, 2008). 
Pensamos que a educação física nesta perspectiva expressa diferentes tipos de linguagem nas quais cada manifestação da cultura corporal possui seu repertório próprio e específico. Assim, cabe à escola e às aulas de educação física o ensino de diferentes linguagens ligadas à cultura corporal no sentido de democratizá-las.

No processo de ensino-aprendizado da capoeira devemos levar em consideração a ambigüidade desta manifestação cultural. As pessoas lutam, jogam, brincam, dançam capoeira e isso faz do seu aprendizado algo bastante enriquecedor. Além disso, deve-se levar em conta sua historicidade contextualizando-a socialmente, pois se trata de uma produção cultural. "[...] A Educação Física brasileira precisa, assim, resgatar a capoeira enquanto manifestação cultural, ou seja, trabalhar com sua historicidade, não desencarná-la do movimento cultural e político que a gerou [...]" (SOARES et al., 1992, p. 76).

A Capoeira, manifestação de origem escrava, que no Brasil faz-se presente desde no mínimo, o início do século XIX, ocupou na sociedade colonial e imperial um papel ligado à marginalidade sendo perseguida e reprimida. Nesse período, sua prática era feita, majoritariamente, por escravos favorecendo sua resistência cultural.

Duramente perseguida com o início da República, numa proporção maior que nos anos anteriores, esta manifestação conseguiu se perpetuar até a década de 1930, quando o momento político favoreceu a Capoeira com o abrandamento da perseguição e com o olhar diferenciado do Governo de Getúlio Vargas sobre as práticas culturais populares. Nesse período uma parcela de seus praticantes adequou-se aos discursos esportivos e a Capoeira tomou novos rumos.

O processo denominado de "reinvenção da tradição"4 da capoeira, termo cunhado por Letícia Reis ( 1997), que deu origem ao que se considera hoje a Capoeira Moderna ${ }^{5}$, foi encabeçado por inúmeros capoeiras que ensinavam essa manifestação no início do século $X X$, o qual desembocou na criação de duas modalidades de capoeira até hoje conhecidas: a Capoeira Regional e a Capoeira Angola.

4. O termo reinvenção da tradição é utilizado por Letícia Reis (1997, p. 100), baseado nos estudos do historiador Hobsbawn (1984), e trata do conceito de "tradição inventada", que é definida como "[...] um conjunto de práticas sociais de natureza ritual ou simbólica, que visam inculcar valores e comportamentos por intermédio da repetição o que implica uma continuidade em relação a um passado histórico apropriado".

5. Este termo utilizado pioneiramente por Letícia Reis ( 1997$)$ é adotado para designar o período após a década de 1930 que se caracterizou pelas transformações as quais a Capoeira passou ao longo dos anos. Estas mudanças, por sua vez, englobam a formulação da Capoeira Regional e da Angola e sua hibridização a partir da migração de capoeiristas baianos para o sudeste e, mais atualmente, pode-se considerar sua internacionalização e as metamorfoses daí decorridas como parte constituinte da Capoeira Moderna. 
Não elencaremos neste momento as diferenças entre estas modalidades, porém Vieira e Assunção (2008, p. 13), analisando os estilos da capoeira atual, afirmam:

[...] é preciso lembrar que a capoeira baiana antes da modernização não era homogênea e uniforme, mas que cada mestre ensinava um conjunto específico de movimentos, ritmos e rituais. Tanto que a capoeira de outros mestres antigos como Waldemar, Cobrinha Verde ou Canjiquinha podia ter características bastante distintas da forma ensinada por Pastinha.

Dessa maneira, nunca houve tradição única e monolítica na capoeira baiana antiga, o que, por sua vez, facilitou que posteriormente cada grupo ressaltasse elementos diversos e mesmo conflitantes da 'tradição'.

Com a descriminalização da capoeira ocorreram ao longo dos anos inúmeros movimentos para sua inclusão em espaços sociais como em escolas, universidades, clubes e academias. A própria área da educação física tentou apropriar-se desta manifestação cultural, porém as apropriações entre capoeira e educação física foram recíprocas e geraram diferentes frutos (SILVA, 2002).

Houve ao longo dos anos vários estudos que pensaram e propuseram métodos e reflexões sobre a capoeira nas aulas de educação física. Neste estudo foi possível levantar bibliograficamente o número de quinze obras ${ }^{6}$ que abordaram este tema, dentre estas, quatro delas foram eleitas para servir de base para a elaboração dos planejamentos do trabalho de campo desta investigação. Como critério de escolha foi levado em consideração a sua relevância e a familiaridade que obtivemos ao longo de nossas experiências didáticas com o material selecionado, foram eles: Capoeira uma proposta para a educação física escolar (ROCHA, 1990); Capoeira: do engenho à universidade (SILVA, 1995); Brincando de capoeira: recreação e lazer na escola (REIS, 1997) e lê, viva meu mestre: a Capoeira Angola da Escola Pastiniana como práxis educativa, (ARAÚjO, 2004).

Com base nessas referências e adotando os pressupostos da concepção crítico-superadora da educação física pensamos em uma proposta de ensinoaprendizado da capoeira que fosse inédita, diante dos demais trabalhos estudados. Neste sentido, buscamos desenvolver um trabalho focado nas experiências desenvolvidas por professores de educação física, da rede pública de ensino, contando com a mediação de um Mestre de Capoeira convidado para compor o quadro de atores reflexivos deste processo. Dessa forma, a capoeira foi compreendida como uma manifestação imersa socialmente e construída coletivamente pelos alunos, professores, Mestre de Capoeira convidado e pesquisadora.

6. Os nomes das obras encontram-se na tese de doutorado de Silva (2009). 
Nossa intenção, portanto, foi contribuir com alguns indícios, apreendidos no trabalho de campo, em como a capoeira, por possuir seu acervo gestual próprio, pode ser ensinada e aprendida como um tipo de linguagem.

\section{O CURSO DE CAPOEIRA PARA OS PROFESSORES, O MESTRE CONVIDADO E OS PLANEJAMENTOS DAS AULAS}

O curso para os professores foi realizado de março a junho de 2007, com encontros semanais (totalizando 15 encontros), às sextas-feiras, das 19:30h às 22:00h, em uma quadra externa, da Faculdade de Educação Física, da UNICAMP. O planejamento das aulas de Capoeira foi feito pelo Mestre convidado e pela pesquisadora e as aulas foram ministradas pelo Mestre com a participação da pesquisadora como auxiliar-docente. A divulgação do curso foi realizada aos professores do Grupo de Estudos e Pesquisas sobre Educação Física Escolar (GEPEFE) e a inscrição dos interessados ocorreu via internet.

A maioria dos professores, dezesseis, era da rede estadual de ensino do Estado de São Paulo e desenvolviam seus trabalhos nas cidades de Campinas, Paulínia e Nova Odessa. Duas professoras eram de redes municipais de ensino, englobando os municípios de Campinas e Vinhedo.

Com relação à participação do Mestre convidado como o responsável em ministrar as aulas e não de outro Mestre, sua escolha deu-se devido à sua vivência no mundo capoeirístico e acadêmico sendo que esse tipo de formação não é muito convencional entre os Mestres de Capoeira. Além disso, Rocha (1990) menciona em seu estudo a importância do trabalho conjunto entre o professor de educação física e o Mestre de Capoeira nas aulas sobre esse conhecimento.

O pressuposto adotado para os planejamentos era que "[...] o planejamento define-se como um instrumento didático necessário, flexível e inacabado." (GUEDES-PINTO et al, 2008, p. 24). Nesse caso buscamos abordar em, um primeiro momento, o ensino-aprendizado da musicalidade e da gestualidade da capoeira, sua história e as reflexões em torno de temas que perpassam sua prática como, por exemplo, preconceitos relacionados à etnia, gênero e classe social e a violência, por vezes, presente nas rodas de capoeira.

As estratégias propostas eram de aulas com dramatização; apresentação de documentários, jogos e vivências da gestualidade, musicalidade, das danças relacionadas à capoeira e de rodas de capoeira, sendo a avaliação processual e dialogada.

7. Grupo de estudos vinculado ao Laboratório de Estudos sobre Corpo, Arte e Linguagem (LABORARTE), da Faculdade de Educação, da UNICAMP/SP. 
Após as oito primeiras aulas, considerando essa perspectiva de flexibilidade e com base numa avaliação realizada entre os docentes e os professores-alunos, o planejamento foi alterado.

Foram acrescentadas mais referências bibliográficas, uma vez que os professores-alunos demonstraram interesse na leitura de artigos de revistas especializadas sobre o assunto e retiramos do cronograma a abordagem de danças ligadas à capoeira.

É interessante colocarmos que à medida que o trabalho foi sendo desenvolvido o que foi sistematizado e apresentado nos planejamentos, tanto no primeiro como no segundo, ganhou novas dimensões. Se, primeiramente a idéia era a de tentar seguir certa ordem na abordagem da gestualidade, musicalidade, ritualidade e dos aspectos históricos da capoeira, o que ocorreu foi a simultaneidade do processo de ensino-aprendizado dos conhecimentos considerados como relevantes. Isso porque determinados temas eram demandados pelos professores-alunos, ou então, o Mestre e a pesquisadora atentavam para a necessidade de estudar um aspecto que em princípio não estava no planejamento na ordem prevista.

Foi na perspectiva dialética que se desenvolveu os temas relativos ao ensinoaprendizado da capoeira. A partir do princípio da "[...] espiralidade da incorporação das referências do pensamento" (SOARES et al., 1992, p. 33) foi possível constatar que os professores-alunos compreendiam determinados assuntos estudados e esse tema tornava-se um trampolim para novos temas relacionados, circunstanciando-os no entendimento ampliado da Capoeira. Por exemplo, o jogo da capoeira faz parte do aprendizado de seus gestos, não é necessário que primeiro se aprenda todo o repertório gestual da capoeira para jogá-la, basta que se domine um repertório gestual básico e entenda suas regras e rituais. Assim, o aprendizado da Capoeira se dá durante o fluir do próprio jogo de capoeira, num processo em que jogo e aprendizado mesclam-se reciprocamente.

O curso iniciou-se, a partir do pressuposto de reflexão pedagógica diagnóstica de ensino da cultura corporal enunciado por Soares et al. (1992) investigando o que os professores-alunos sabiam sobre capoeira: se conheciam algum trabalho nas aulas de educação física ou em escolas; se já tinham praticado-a e, em caso afirmativo, em qual grupo e modalidade de Capoeira; indagamos também quais as expectativas que tinham sobre o curso. Essas perguntas foram realizadas através de um questionário estruturado ${ }^{8}$, com perguntas abertas, as quais os professores

8. O questionário respondido pelos professores foi validado em 2006, por ocasião de um projeto piloto da abordagem do conteúdo Capoeira, nas aulas de educação física, em uma escola pública de Campinas/SP, e contou com a participação de quatro professores que ministravam aulas de educação física nessa escola e que responderam ao questionário. 
responderam e da filmagem da apresentação de cada um deles realizada para o grupo no primeiro encontro.

A primeira aula consistiu na apresentação do plano de aulas do curso, dos docentes e dos professores-alunos, bem como, na apresentação de um pouco da história da capoeira através de um documentário. Já no segundo encontro houve a dramatização das leituras realizadas, em sala de aula, baseadas em artigos de revistas especializadas no tema, seguido de discussões sobre os textos e de mitos da tradição oral dessa manifestação. A partir do terceiro encontro até o final do curso, a regência das aulas concentrou-se com o mestre convidado e foi ele quem coordenou os trabalhos cabendo a pesquisadora, a filmagem e a colaboração naquilo que se fazia necessário.

A rotina das aulas seguia um ritual que se iniciava com o exercício de tocar os instrumentos musicais da capoeira e cantar. Nesse momento, os professores-alunos eram orientados a revezarem-se no aprendizado dos instrumentos, de modo que todos vivenciassem um pouco cada instrumento. $\bigcirc$ mestre demonstrava como deveria ser tocado cada um, o ritmo de cada "toque", explicava o seu significado, realizava exercícios de cantos para que os professores-alunos pudessem conhecer um pouco do repertório da capoeira.

A aula continuava com a vivência da gestualidade. Nessa parte, as estratégias de ensino pautavam-se na demonstração dos gestos e imitação destes. Inicialmente, o mestre ensinava os golpes, contragolpes, defesas ou acrobacias, fora do contexto de jogo, para que os professores pudessem perceber a técnica do gesto e executá-lo.

À medida que o repertório gestual era ampliado, a complexidade da demonstração dos exercícios a serem executados era aumentada, como por exemplo, a do mestre demonstrar um golpe e a pesquisadora um contragolpe ou defesa. Essa lógica de ensino-aprendizado prosseguia com a execução de um golpe (realizado pela pesquisadora ou pelo mestre), uma defesa, um contragolpe, outra defesa ou uma acrobacia. Os professores-alunos, ao verem a execução dos gestos, no caso das interações gestuais, como perguntas e respostas, tentavam, em duplas, reproduzir o que viram. Enquanto os professores-alunos exercitavam-se, o Mestre acompanhava-os e corrigia a execução dos gestos das duplas. Esse exercício das interações gestuais é um dos caminhos para o aprendizado do jogo da capoeira, pois a partir de algumas seqüências, predeterminadas pelo Mestre, os professores percebiam que é possível combinar os diferentes gestos e elaborar jogadas. Desse

9. No mundo capoeirístico o "toque" determina a dinâmica do jogo e pode ou não denominar o tipo de jogo ou modalidade da capoeira. 
modo, podemos comparar a capoeira a um jogo de xadrez, no qual existem várias peças e, de acordo com as jogadas realizadas pelo parceiro, escolhe-se a peça favorável e o caminho a ser seguido visando a uma boa jogada e desencadeando novas respostas, continuamente, até o final do jogo.

\section{O PROCESSO DE ENSINO-APRENDIZADO DOS PROFESSORES-ALUNOS}

Um dos métodos de ensino-aprendizado utilizado no curso foi a da demonstração, seguida da repetição do que foi proposto pelo mestre. Na maioria das vezes, a execução do que havia sido demonstrado, tinha o auxílio dos mais experientes, aqueles professores-alunos que já praticaram Capoeira ou que tinham maior facilidade em aprender o que estava sendo ensinado. Além disso, a execução dos gestos ensinados em duplas, como em um jogo, também mostrou-se como uma forma bastante presente nos processos de ensino-aprendizado do mestre. No decorrer dos exercícios em duplas ou individuais a correção do gesto, ao longo do aprendizado, foi uma tarefa constante do Mestre que, eventualmente, contou com a ajuda da pesquisadora. Neste caso, podemos considerar esse modo de ensino-aprendizado como sócio-interacionista, no qual o Mestre, os colegas de turma, a pesquisadora, as leituras e os documentários fazem a mediação do que é ensinado. De acordo com Vygostky (| 99|, p. 99): "[...] os animais são incapazes de aprendizado no sentido humano do termo; o aprendizado humano pressupõe uma natureza social específica e um processo através do qual as crianças penetram na vida intelectual daquelas que as cercam". Isso que distingue o processo de imitação que um macaco pode fazer, com a imitação que o ser humano faz. Entre essas ações imitativas existe uma grande diferença que é a produção de cultura, as intervenções dos que participam das aulas produzindo mudanças mediadas pela convivência social e da linguagem, algo que os animais não são capazes de elaborar.

No decorrer do curso houve situações muito interessantes que demonstram os diferentes sentidos e significados de cada gesto da capoeira apreendido pelos professores, como as descrições a seguir.

No quinto encontro, foi pedido aos professores, após tentarem executar os gestos da negativa ${ }^{10}$ individualmente, que realizassem em duplas essa proposta. Os participantes realizaram os gestos por aproximadamente cinco minutos, de forma tranqüila, pois muitos descansavam os braços entre uma tentativa e outra.

Aproveitando o cansaço dos alunos, o mestre pôs-se a nomear os gestos e a explicá-los através de uma demonstração resumida de tudo que foi aprendido nas

10. Defesa da capoeira, no qual o capoeirista apóía o peso de seu corpo em uma flexão de um dos braços, apoiado lateralmente no chão, estendendo uma das pernas à frente. 
aulas anteriores. Nesse momento houve a recuperação dos "conteúdos" gestuais e o início das interações entre os gestos.

Ginga, negativas, esquivas, giros, meia lua de frente ${ }^{\prime \prime}$, tudo se misturando num improviso. O mestre chamou duas professoras, uma de cada vez, e mostrou a cada uma delas, e ao grupo, o que poderia ser feito com aqueles movimentos aprendidos, mostrando que o gesto corporal, muitas vezes não precisava ser executado, mas a intenção demonstrada determinava a reação do parceiro de jogo.

Ele destacou a importância de exibir a intenção do gesto que constrói o sentido que as jogadas vão adquirindo construindo significados diferentes.

No caso da meia lua de frente, por exemplo, ele enfatizou que a perna não precisava ser erguida muito alto, bastava ser levantada próxima ao solo, mas a perna de apoio deveria estar flexionada e o tronco insinuaria a deflagração do gesto, com velocidade ou não, dando a intensidade que se desejaria, de acordo com a gestualidade. A segurança demonstrada pelo Mestre refletia em seu corpo a intenção, tanto que na exemplificação do gesto, a professora que o acompanhava era "convencida", gestualmente, do golpe a ser desferido, respondendo com uma esquiva. Entretanto, dissimuladamente, ele "desmontava" o gesto e partia para outro movimento. A construção gestual era pautada na intenção, muito mais do que na execução.

Então, ele solicitou que, em duplas, os professores exercitassem os gestos aprendidos buscando fazer um pequeno jogo. Em meio aos alunos o Mestre ia corrigindo, orientando e jogando com os participantes.

Em seguida, chamou os professores para uma roda de conversa e falou:

Vamos falar uma coisa para todos. Taí algumas informações! E a gente começou a montar o nosso quebra-cabeça, várias peças, umas vão encaixando e a gente vai... Eu vou começar a trabalhar com vocês, como lição de casa, porque a gente não vai se ver mais, nem na segunda, nem na quarta, só na outra sexta, porque a gente começou a fazer um movimento, na aula passada, uma esquiva (ele mostrou o movimento) a partir da esquiva a gente fazia assim (e mostrou uma inversão do corpo, pés para cima e as duas mãos no chão), ia e virava de costas para o outro e parava em pé. Aqui está o tal de aú, se eu falasse que a gente estava começando a fazer o aú [...] Nossa ![...] (MESTRE CONVIDADO)

Então, ele fez um gesto para fazer uma estrela, que é um gesto característico da ginástica artística, de forma bem marcada, com a ponta dos pés bem estendidos, com os braços estendidos para cima da cabeça e uma postura de ginasta, os professores riram e comentavam várias coisas juntas, incompreensíveis.

| I. Todos são nomes de gestos do repertório do jogo da capoeira. 
E, então, o mestre mostrou o gesto da esquiva com o giro, mas ao invés de passar as pernas, de um lado para o outro, pisando no chão, ele deu um saltito. Mostrou para os professores o mesmo gesto, mas partindo do lado contrário e comentou rindo, com ar irônico:

Tem um lado que é maravilhoso, eu sei, mas tem que tentar dos dois lados. (MESTRE CONVIDADO)

O significado do gesto do aú da capoeira e da estrela da ginástica artística são díspares, apesar de terem uma técnica gestual muito parecida. Conforme a narrativa, percebe-se que o aú, no caso descrito, teve a intenção de dar continuidade a uma jogada da capoeira, podendo servir como uma defesa ou uma aproximação ao parceiro para a execução de um golpe. Já a estrela da ginástica tem uma ação definida que é a de demonstrar sua execução plasticamente perfeita, dentro das regras dessa modalidade esportiva. Percebe-se mais um diferencial na execução destes gestos, a estrela pode fazer parte de uma composição coreográfica da ginástica artística que será treinada e repetida do mesmo modo, para que sua execução seja a mais correta possível dentro do que é estabelecido pelas regras. Já o aú pode ser executado a qualquer momento dentro do jogo da capoeira, desde que faça parte de um contexto no qual tenha sentido, seja como uma defesa ou como uma aproximação ou até mesmo a indução a outro gesto, como por exemplo, mostrar certa vulnerabilidade para que o parceiro faça um golpe e contra atacá-lo desarmando o aú fazendo um contra golpe.

Percebendo a capoeira como uma linguagem corporal, podemos observar na descrição feita da aula que a execução dos gestos encadeados entre si, em interação com o parceiro, cria um diálogo corporal. A vivência desse processo foi sendo apropriado pelos professores, apesar das dificuldades relativas à execução dos gestos e daquilo que poderíamos chamar de linguagem do jogo.

É como se as palavras fossem os gestos da capoeira e que quando se encadeia uma palavra à outra é possível construir uma frase que dentro de determinado contexto tem um sentido e significado. Porém, se não sabemos executar o gesto não é possível construir uma jogada e, consequentemente, o "diálogo" fica prejudicado, pois faltam os "recursos linguísticos". Ou então, quem domina mais o gesto acaba dominando o diálogo.

Percebendo esse modo de encadeamento dos gestos e os diálogos que são possíveis de serem realizados no jogo da capoeira houve uma roda de conversa bastante interessante na oitava aula. 
A Profa. $M^{12}$ contou que começou a trabalhar com suas turmas elementos que estavam sendo desenvolvidos no curso. Ela declarou que já tinha uma experiência de cinco anos com o conteúdo capoeira em suas aulas, pois é capoeirista e, a partir de suas vivências, abordou alguns pontos para o ensino-aprendizado dessa manifestação. De acordo com suas colocações, o que ela havia considerado mais relevante das aulas do mestre foi a continuidade dos gestos da capoeira. Ela disse que partindo do que já trabalhava anteriormente, ela passou a acrescentar a continuidade dos gestos. E, concomitantemente à capoeira, ela traçou paralelos em suas aulas, com os conhecimentos da ginástica, uma vez que seus alunos questionavam sobre os nomes dos gestos e similaridades em sua execução na Ginástica Artística e na Capoeira. Ela reinventou ou adaptou algumas brincadeiras com o que estava aprendendo no curso e com a experiência que desenvolveu ao longo dos anos percebeu que o resultado obtido estava muito bom.

O mestre fez o seguinte comentário:

O que é interessante $[. .$.$] Primeiro [...] quando você vai fazendo blocos e depois tentando$ ligar fica muito mais difícil. (MESTRE CONVIDADO)

Estes blocos referem-se aos exercícios em duplas nos quais a execução dos golpes e contragolpes ficam restritos, não se dá continuidade aos movimentos para se formar novas jogadas. Os jogadores executam somente dois gestos de cada vez, ou em cada bloco, golpe e contra golpe, que terminam em si mesmos, sem dar continuidade ou fazer o aluno refletir acerca da possibilidade de novos gestos a serem incorporados aos dois iniciais. Esta forma de ensino-aprendizado da capoeira é adotado por vários mestres, inclusive por aqueles que ensinaram Capoeira ao nosso mestre convidado, de acordo com seus depoimentos em aulas.

Entretanto, a metodologia que o mestre convidado desenvolveu também contemplava esse tipo de exercício. A diferença é que, após a execução do que é denominado de "blocos", ele dava continuidade à seqüência de movimentos, ou seja, há o desdobramento dos gestos que ao invés de formarem uma "pequena frase gestual" formam "longas frases gestuais", pois há mais gestos para formar novas interações.

O mestre prossegue seu raciocínio sobre o que disse a Profa. M:

[...] O aú, que é diferente da estrela (da Ginástica Artística), (sua) postura. Não! Faz estrela para depois fazer aú. Você constrói uma coisa para depois desconstruir... (MESTRE CONVIDADO)

12. Os professores neste artigo são identificados por letras para preservar sua identidade. 
Nesse momento, outra professora que tem uma vivência no campo da Ginástica Artística e na Ginástica Geral colocou:

Estava comentando com a Profa. G, a minha vivência, na minha cabeça já está partindo de uma desconstrução, porque eu tenho um corpo construído na ginástica. (PROFA. C)

O mestre completou:

Encaixado [...] e aqui a gente vai desencaixar. (MESTRE CONVIDADO)

Essa forma de compreensão das diferentes linguagens que compõe o acervo da cultura corporal é que fez dos debates do curso um material riquíssimo no processo de ensino-aprendizado da capoeira para os professores e que mais adiante Ihes serviu como referências para a abordagem da capoeira em suas aulas.

\section{CONSIDERAÇÕES FINAIS}

O propósito desse texto foi o de discutir possibilidades de ensino-aprendizado da capoeira na educação física escolar compreendendo-a como uma manifestação cultural composta por gestualidade, musicalidade, aspectos históricos e ritualísticos com base nas experiências desenvolvidas em um curso de formação continuada de capoeira para professores.

É importante mencionarmos que tanto a pesquisadora, como o Mestre convidado, tiveram o cuidado de planejar aulas nas quais os professores-alunos se sentissem motivados a participar e adquirir gosto pela capoeira. Isso porque pensamos que se as pessoas tiverem a chance de praticá-la de forma prazerosa, poderão divulgá-la e, no caso dos professores-alunos, ensiná-la democratizando, assim, este conhecimento. Sabemos que se em um primeiro momento, essa manifestação cultural pode causar estranheza, devido às suas peculiaridades, esse sentimento pode ser dissipado a partir de uma vivência que favoreça a produção de sentidos e significados por parte de quem a estuda/pratica.

De acordo com o depoimento dos professores-alunos este objetivo foi alcançado, pois muitos avaliaram as aulas e o processo de ensino-aprendizado de forma positiva. Entretanto, foi relatado pelo grupo que mesmo apreendendo o jogo da capoeira e sua gestualidade, os professores-alunos tiveram dificuldades quanto ao aprendizado da musicalidade e a insuficiência de tempo para as vivências gestuais. Na roda de conversa, a maioria alegou que somente um encontro semanal não era suficiente para exercitar o que era trabalhado nos encontros.

Com relação a musicalidade eles consideraram seu aprendizado de extrema importância, seus depoimentos apontaram grande interesse e prazer no exercício do 
canto e do toque dos instrumentos musicais, mas, muitos deles relataram que não conseguiriam sozinhos ministrar esse tipo de vivência em suas aulas na escola.

No que diz respeito à apreensão da gestualidade, percebemos que foi bastante difícil este aprendizado para alguns que não estavam acostumados com atividades que demandassem um aprimoramento rítmico. Já para outros, a dificuldade foi a execução das acrobacias, como aquelas que englobavam as inversões corporais. Mas, o ponto positivo e principal que foi notado refere-se à apreensão dos sentidos e significados dos gestos da capoeira demonstrado pelos professores-alunos. Este fato pode ser visto a partir da participação dos professores em jogos de Capoeira e de suas falas registradas ao longo do curso.

O contato com um Mestre de Capoeira como mediador do curso repercutiu de forma bastante positiva. Entretanto, fica a dúvida se essa parceria entre o professor de educação física e o Mestre de Capoeira poderia ocorrer no cotidiano escolar. Talvez não seria inviável, mas haveria uma série de dificuldades para a implantação de um trabalho nesse nível que englobaria desde a falta de verbas para a contratação de Mestres de Capoeira para as escolas, como o modo de ensino-aprendizado que cada Mestre adotaria, pois não há uma uniformidade com relação à abordagem da Capoeira no meio capoeirístico.

Com relação ao tipo de formação do professor para o ensino da Capoeira nas aulas de educação física não foi possível estabelecer um consenso. Pelo que vimos, é possível ponderar que o contato do estudante de educação física com a Capoeira possa ocorrer por meio de uma disciplina na graduação e assim ele teria acesso a este tipo de conhecimento. Entretanto, essa experiência pode não ser determinante para que ele ministre aulas de Capoeira na escola. Na pesquisa nem todos os professores que tiveram contato com esta manifestação, anteriormente ao curso, desenvolviam aulas sobre esse conhecimento e, por outro lado, havia professores que sem nunca terem feito um curso ou uma disciplina que tratasse especificamente da Capoeira ministravam aulas sobre esse tema.

Entendemos que são as condições sociais de produção na qual o professor encontra-se inserido que vão impulsionar a escolha (ou não) da Capoeira para compor o rol das manifestações da cultura corporal a serem estudadas em suas aulas. Dentre tantos condicionantes, pode-se considerar a estrutura e organização da escola, incluindo espaço físico, gestão, comunidade escolar, alunos, políticas educacionais, etc.

Por fim, vemos que a Capoeira pode ser ensinada e apreendida, com base nas interações gestuais, configurando um tipo de linguagem, inserida em determinado contexto social e histórico. Cada jogada, cada gesto e resposta gestual ganha um diferente sentido e significado expressados por meio dos corpos que travam diálogos diferentes, próprios e singulares. 


\section{Capoeira classes in physical education: some notes on processes for teaching-learning for teachers}

ABSTRACT: This article talk about Capoeira and its processes of teaching and learning from a qualitative research which included in the first stage of fieldwork a continued course of education for Capoeira's teachers. We highlighted the understanding that we have about Capoeira and the importance of their inclusion in physical education classes at school. We detail how the course was for teachers in which we incluided as a participant observer, and discuss the teaching-learning processes developed. Finally, we point out some evidences about the diffculties presented by the participants, the positives experiences elapsed and the possibility of approaching the teaching of Capoeira based on gestural interaction.

KEYWORDS: Capoeira; physical education; continuing education of teachers; teaching and learning.

\section{Capoeira en las clases de educación física: algunas notas sobre los procesos del enseñanza-aprendizaje de profesores}

RESUMEN: Este artículo es sobre la capoeira y sus procesos de enseñanza y aprendizaje a partir de una investigación cualitativa que incluyó en su primera fase de trabajo de campo un curso de formación continuada de Capoeira para profesores. En el se destaca la comprensión que tenemos acerca de la Capoeira y la importancia de su inclusión en las clases de educación física en la escuela. Se detallan cómo el curso fue para los profesores, en los que se le incluyen como observadora participante, y se discuti los procesos de enseñanza-aprendizaje que se desarrolló. Por último, señalamos algunas evidencias en relación a las dificultades presentadas por los participantes, las experiencias positivas transcurridas y la posibilidad de acercarse a la enseñanza de la Capoeira basada en la interacción gestual.

PALABRAS CLAVE: Capoeira; educación fisica; formación continuada de profesores; enseñanza-aprendizaje.

\section{REFERÊNCIAS}

ARAÚJO, R. C. lê, viva meu mestre: a capoeira angola da escola pastiniana como práxis educativa. 2004. 25 I f. Tese (Doutorado em Educação)-Faculdade de Educação, Universidade de São Paulo, São Paulo, 2004.

AYOUB, E. Brincando com o ritmo na educação física. Revista presença pedagógica. Belo Horizonte, v. 6, n. 34, p. 44-57, jul./ago. 2000.

BOGDAN, R.; BIKLEN, S. Investigação qualitativa em educação. Porto: Porto Editora, 1994.

GUEDES-PINTO, A. L. (Coord.). A organização do tempo pedagógico e o planejamento de ensino. In: BRASIL. Secretaria de Educação Básica. Pró-Letramento: Programa de Formação Continuada de Professores das Séries Iniciais do Ensino Fundamental: alfabetização 
e linguagem. Brasília: MEC/SEB/SEED, 2008. Disponível em: http://portal.mec.gov.br/index. php? option $=$ com_content\&view $=$ article\&id $=12616 \% 3$ Aformacao\&ltemid $=698$. Acesso em: 4 ago. 20 I I. 3 If.

NEGRINE, A. Instrumentos de coleta de informações na pesquisa qualitativa. In: MOLINA NETO, V.; TRIVIÑOS, A. N. S. (Org.). A pesquisa qualitativa na Educação Física. 2. ed. Porto Alegre: Ed. da UFRGS, 2004. p. 61-93.

REIS, A. L. T. Brincando de capoeira: recreação e lazer na escola. Brasília: Valcy, 1997.

REIS, L. V. S. O mundo de pernas para o ar: a capoeira no Brasil. São Paulo: Publisher Brasil, 1997.

ROCHA, M. A. Capoeira uma proposta para a educação física escolar. 1990. 80 f. Trabalho de Conclusão de Curso (Especialização em Educação Física Escolar)-Faculdade de Educação Física, Universidade Estadual de Campinas, Campinas, 1990.

SÃO PAULO. Governo do Estado de São Paulo. Secretaria de Economia e Planejamento. Disponível em: <http://www.ppa.sp.gov.br/perfis/PerfiRMCampinas.pdf>. Acesso em: 24 de set. 2008.

SILVA, G. de O. Capoeira: do engenho à universidade. 2. ed. São Paulo: CEPEUSP, 1995.

SILVA, P. C. da C. O ensino-aprendizado da Capoeira nas aulas de Educação Física escolar. 2009. 26 I f. Tese (Doutorado em Educação)-Faculdade de Educação, Universidade Estadual de Campinas, Campinas, 2009.

A Educação Física na roda de Capoeira: entre a tradição e a globalização. 2002. 238 f. Dissertação (Mestrado em Educação Física)-Faculdade de Educação Física, Universidade Estadual de Campinas, Campinas, 2002.

SOARES, C. L. et al. Metodologia do ensino de Educação Física. São Paulo: Cortez, 1992.

SOARES, C. E. L. A capoeira escrava e outras tradições rebeldes no Rio de Janeiro ( 808 - 1850). Campinas: UNICAMP: Centro de Pesquisa em História Social da Cultura, 2001.

VIEIRA, L. R.; ASSUNÇÃO, M. R. Os desafios contemporâneos da capoeira. Revista Textos do Brasil, Brasília, v. I, n. 14, 2008. p.7-19.

VYGOTSKY, L. S. A formação social da mente: o desenvolvimento dos processos psicológicos superiores. 4. ed. São Paulo: Martins Fontes, 1991.

Recebido: 14 maio 2010

Aprovado: 29 dez. 2010

Endereço para correspondência

Paula Cristina da Costa Silva

Rua Prof. Elpídio Pimentel, 40 I - ap. 202 - Jd. da Penha

Vitória/ES - CEP: 29.060-170 